\title{
Role of Peroral Endoscopic Myotomy (POEM) in the Management of Esophageal Diverticula
}

\author{
Bogdan P. Miutescu', Sarah Khan ${ }^{2}$, Shruti Mony ${ }^{3}$ and Mouen A. Khashab ${ }^{3}$ \\ 1'Department of Gastroenterology and Hepatology, Victor Babeș University of Medicine and Pharmacy, Timișoara, Romania, \\ '2Department of Medicine, Saint Agnes Hospital, Baltimore, MD, USA, ${ }^{3}$ Department of Gastroenterology and Hepatology, Johns Hopkins \\ Hospital, Baltimore, MD, USA
}

Esophageal diverticula are uncommon; however, when present, they can cause symptoms of dysphagia, regurgitation, and chest pain. Based on location and pathophysiological characteristics, they are classified as pulsion- and traction-type diverticula. In the past, the open surgical approach was the only treatment available; however, in the past few decades, transoral incisionless approaches in the form of rigid and flexible endoscopy have gained popularity. Diverticular peroral endoscopic myotomy has emerged as an alternative treatment option. In this paper, we reviewed the role of peroral endoscopic myotomy as a treatment option for different types of esophageal diverticula. Although a safe and effective procedure, this novel submucosal tunneling technique for the treatment of esophageal diverticula requires further validation, and head-to-head comparisons between the different approaches for the treatment of esophageal diverticula are warranted. Clin Endosc 2020;53:646-651

Key Words: Diverticulum; Endoscopy; Esophagus; Myotomy

\section{INTRODUCTION}

Esophageal diverticula are rare and can be located in the pharyngeal esophagus, mid-esophagus, or distal esophagus. Esophageal diverticula are outpouchings of the esophagus that have a prevalence of approximately $0.06 \%-4 \%$ based on radiologic and endoscopic studies. ${ }^{1}$ The treatment for esophageal diverticula is septotomy, which can be achieved through several different ways: open surgery, rigid endoscopy, or flexible endoscopy. ${ }^{2}$ More recently, with advancements in endoscopic techniques and instrumentation, peroral endoscopic myotomy (POEM) has gained worldwide acceptance for the treatment of some esophageal motility disorders (EMDs). ${ }^{3}$ The proce-

Received: October 2, 2020 Revised: November 5, 2020

Accepted: November 5, 2020

Correspondence: Mouen A. Khashab

Department of Gastroenterology and Hepatology, Johns Hopkins Hospital, 1800 Orleans St, Baltimore, MD 21287, USA

Tel: +1-443-287-1960, Fax: +1-410-500-4267, E-mail: mkhasha1@jhmi.edu ORCID: https://orcid.org/0000-0001-5085-7908

(c) This is an Open Access article distributed under the terms of the Creative Commons Attribution Non-Commercial License (http://creativecommons.org/ licenses/by-nc/3.0) which permits unrestricted non-commercial use, distribution, and reproduction in any medium, provided the original work is properly cited. dure uses the principles of submucosal endoscopy, and over the last decade, has been successfully used to treat various gastrointestinal diseases, including achalasia, gastroparesis, and subepithelial tumors. ${ }^{4}$ In addition to these indications, POEM has also been used in the treatment of esophageal diverticula. In 2016, Li et al. described submucosal tunneling endoscopic septum division for the treatment of a patient with Zenker's diverticulum (ZD). ${ }^{5}$ In this review, we have described the different types of esophageal diverticula and the role of POEM as a treatment option for esophageal diverticula.

\section{CHARACTERISTICS AND PATHOPHYSIOLOGY OF ESOPHAGEAL DIVERTICULA}

Esophageal diverticula can be divided into two types: the pulsion diverticulum and traction diverticulum. The pulsion diverticulum is a false diverticulum. Pulsion diverticula occur because of increased intraluminal pressure (usually due to EMDs), which causes herniation of the mucosal and submucosal layers. ${ }^{6}$ This can be seen in ZD if it is located above the 
upper esophageal sphincter or in an epiphrenic diverticulum if it is located within $10 \mathrm{~cm}$ of the gastroesophageal junction. The traction diverticulum is a true diverticulum. It is an outpouching that involves all three layers: the mucosal, submucosal, and muscular layers. It occurs because of external traction on the esophageal wall from chronic mediastinal inflammation due to diseases such as pulmonary tuberculosis and histoplasmosis lymphadenopathy. ${ }^{6}$

$\mathrm{ZD}$ is a pulsion-type pharyngoesophageal pseudodiverticulum. $\mathrm{ZD}$ is the most common type of esophageal diverticula, with a reported prevalence ranging from $0.01 \%$ to $0.11 \% .{ }^{8}$ It is a sac-like outpouching of the mucosa and submucosa in the area of muscle weakness between the horizontal fibers of the cricopharyngeal muscle and oblique fibers of the inferior pharyngeal constrictor known as Killian's triangle. ZD is typically found in middle-aged and elderly patients, presenting during the sixth, seventh, or eighth decade of life. It may be asymptomatic but can present with symptoms such as dysphagia and odynophagia. ${ }^{7}$ Treatment is recommended for patients with symptoms because it can lead to complications such as aspiration and failure to thrive. Surgical options include diverticulectomy, diverticulopexy, diverticular inversion with or without myotomy, and myotomy alone. ${ }^{9}$ However, as symptoms of ZD generally occur in the late decades of life, surgical treatment is associated with increased morbidity and mortality rates of up to $30 \%$ and $3 \%$, respectively. ${ }^{10}$ Therefore, the use of a minimally invasive endoscopic approach has become increasingly popular. Endoscopic treatment generally includes performing a septotomy using several devices originally developed for endoscopic submucosal dissection. More recently, POEM has been employed for the management of $\mathrm{ZD}$.

Epiphrenic diverticula (ED) are another type of diverticula that tend to be located in the distal part of the esophagus. It has an estimated prevalence of $0.015 \%{ }^{11}$ Its pathogenesis is considered to be secondary to EMDs and is associated with the congenital weakness of the esophageal wall. Treatment options for ED include surgical treatment by removing the diverticulum with myotomy through the lower esophageal sphincter (LES) and fundoplication or endoscopic treatment through flexible endoscopy and POEM. ${ }^{12}$

The Killian-Jamieson (KJ) diverticulum is a mucosal protrusion below the cricopharyngeal muscle through an area of anatomical weakness, the Killian's dehiscence. ${ }^{8}$ It is commonly asymptomatic but can also present symptoms similar to ZD. However, KJ diverticulum can be distinguished from ZD by its location. ZD mainly occurs in the anterolateral wall of the cervical esophagus, while KJ diverticulum occurs mainly in the posterior aspect of the esophagus.

Traction diverticula (TD) usually occur in the thoracic esophagus. They occur because of chronic inflammation, adhesions, and fibrotic states that pull the wall of the esophagus outward, creating a true diverticulum. The apex of the bulge is located superior to the opening and therefore remains relatively small and rarely produces symptoms. TD are frequently associated with mediastinal inflammation due to pulmonary tuberculosis, histoplasmosis, and other infections. TD usually present with symptoms such as dysphagia, regurgitation, belching, retrosternal pain, heartburn, and epigastric pain. The treatment of TD involves treating the underlying cause; this can be performed with surgical resection along with esophageal myotomy. ${ }^{13}$

\section{PROCEDURAL TECHNIQUE OF DIVERTICULAR PERORAL ENDOSCOPIC MYOTOMY}

The general principles for diverticular POEM (D-POEM) are the same as those of POEM performed for achalasia. For this, the patients are placed under general anesthesia in the supine position. A high-definition gastroscope with a distal attachment is used to perform the procedure using carbon dioxide for insufflation, an electrosurgical unit, a variety of dissection knives, and hemostatic devices. The procedure has four main steps (Fig. 1, Supplementary Video 1). The first step is to create a bleb after submucosal injection. This is traditionally created approximately $2 \mathrm{~cm}$ proximal to the diverticulum, where a $1.5-\mathrm{cm}$-long mucosal incision is performed. More recently, the submucosal bleb and incision can be created over the septum itself. This method is used for patients with challenging anatomy; however, it may be considered in traditional cases as well. ${ }^{14}$ The second step is submucosal tunneling on both sides of the septum using spray coagulation until the bottom of the septum is reached to ensure sufficient working space and an efficient myotomy. Extreme precaution is taken to avoid injuring the mucosa while tunneling. In ED (Fig. 2, Supplementary Video 2) associated with underlying motility disorders such as achalasia or achalasia-related disorders, the length of the submucosal tunneling has to be extended $2-3 \mathrm{~cm}$ beyond the gastroesophageal junction, to perform a concomitant myotomy of the LES. The third step of D-POEM is the septum division. Under direct endoscopic vision, the septum is completely dissected to the bottom of the $\mathrm{ZD}$, and the myotomy is extended $1 \mathrm{~cm}$ up to the proximal esophagus to ensure a complete septotomy. In the setting of esophageal outflow obstruction and ED, after complete dissection of the septum, the myotomy is extended $2-3 \mathrm{~cm}$ beyond the gastroesophageal junction for a complete division of the LES. Finally, in the 

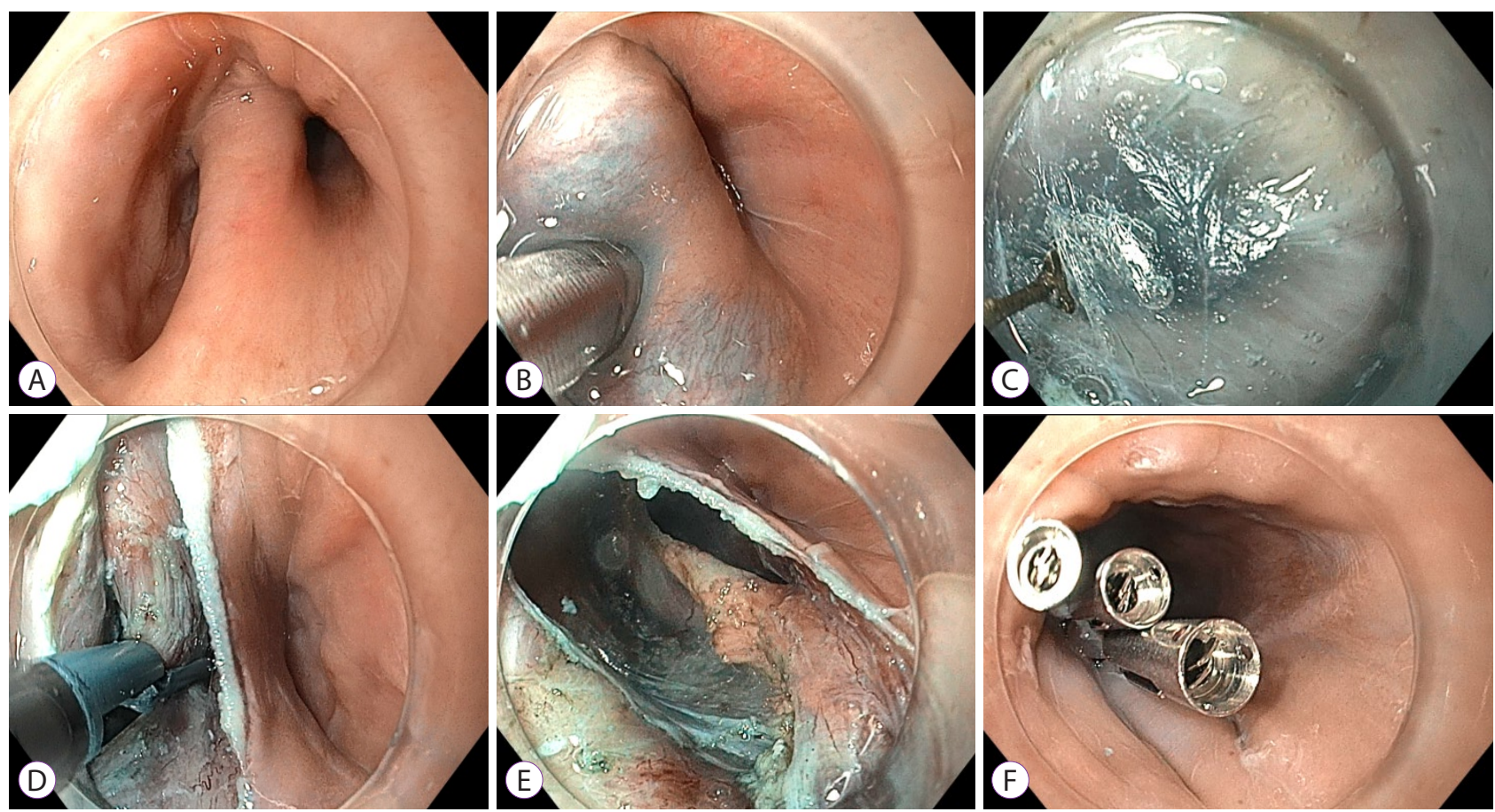

Fig. 1. Endoscopic images of the Zenker's diverticulum using the peroral endoscopic myotomy technique. (A) Endoscopic view of Zenker's diverticulum with a clear cap attached to the endoscope tip. (B) A mucosal bleb is created over the septum. (C) Tunneling is performed along both sides of the septum using the triangular tip knife. (D) Following septum exposure, septotomy is performed using the rotatable scissors-type knife. (E) Septotomy is extended to the base of the septum. (F) Closure using clips.

fourth step, the gastroscope is retracted, and the mucosal entry is closed with clips. Any mucosal perforation or laceration should also be closed with hemostatic clips.

\section{TREATMENT OUTCOMES OF ESOPHAGEAL DIVERTICULA}

The treatment of ZD has evolved significantly. Historically, treatment was limited to an open surgical approach through a neck incision with subsequent myotomy of the upper esophageal sphincter and removal or suspension of the diverticulum. ${ }^{9}$ In the past four decades, alternative transoral incisionless approaches have been developed that use both rigid and flexible endoscopy. ${ }^{15}$ Flexible endoscopic modalities for ZD consist of performing a septotomy using a myriad of endoscopic tools. Although the reported clinical success rate is greater than $90 \%$ with a low adverse event rate of $5 \%$, the median clinical recurrence is $10.5 \%$, with reported recurrence rates of up to $35 \%{ }^{2}$ The relatively high recurrence rate is attributed to incomplete septotomy. ${ }^{16}$

The submucosal space has been successfully used for per- forming endoscopic myotomy during POEM. Along the same lines, POEM could be an optimal technique for performing Zenker's myotomy (septotomy) as submucosal tunneling enables complete exposure and division of the septum. This, in turn, may result in the reduction and potential elimination of the risk of symptom recurrence. The novel concept of using POEM in the treatment of esophageal diverticula (D-POEM) was recently established. ${ }^{5,17,18}$

\section{OUTCOMES OF DIVERTICULAR PERORAL ENDOSCOPIC MYOTOMY}

As previously mentioned, esophageal diverticula are common among the elderly; thus, patients are often poor candidates for surgery. Therefore, less invasive, safer, and more effective procedures are desirable. The POEM technique may overcome some limitations of surgery and standard flexible endoscopy. ${ }^{19}$ In a multicenter study conducted by Yang et al., the safety and efficacy of POEM in treating ZD was analyzed in 75 patients. ${ }^{20}$ Both technical and clinical success rates were high ( $97.3 \%$ and $92 \%$, respectively), and adverse events 

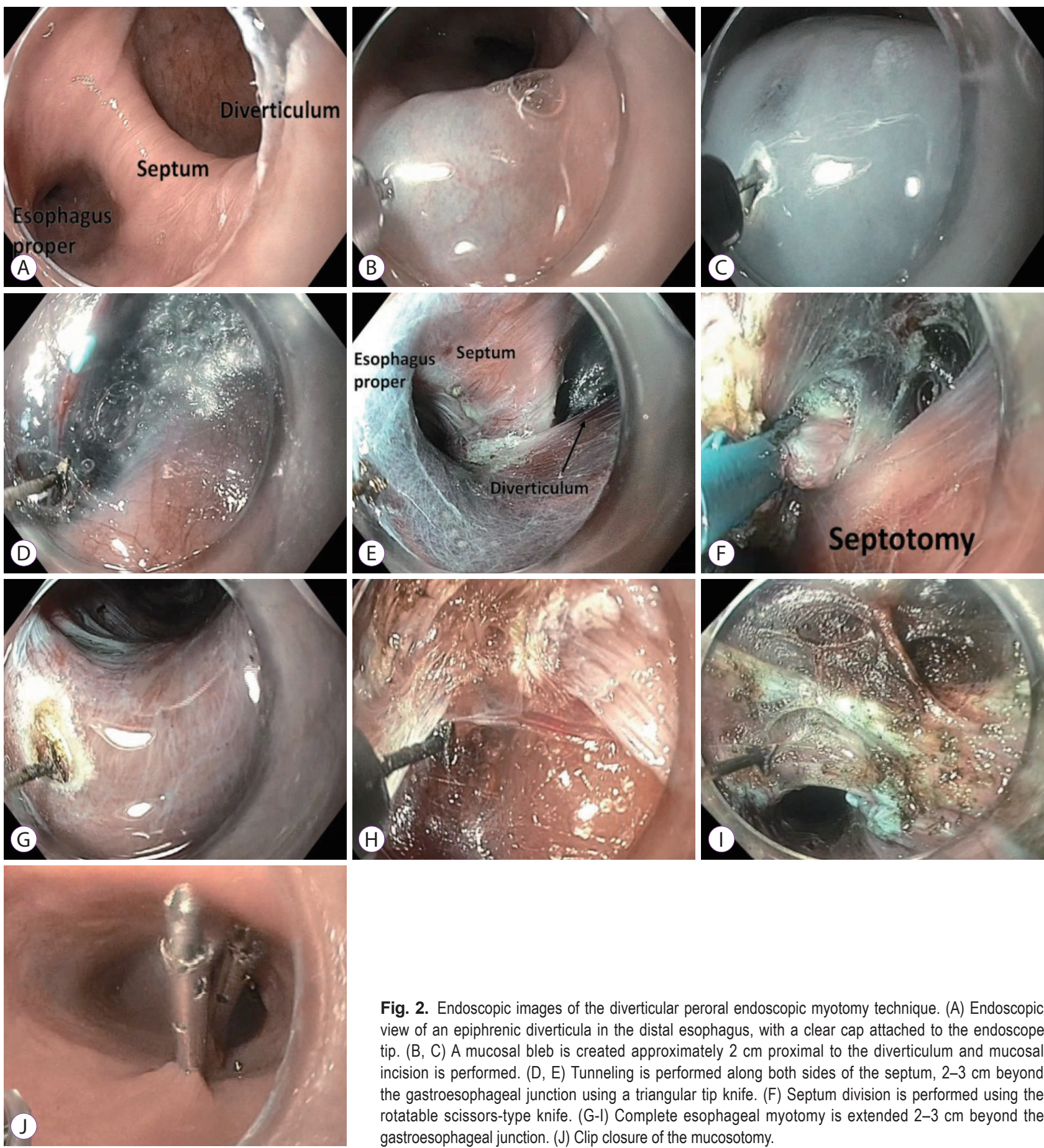

Fig. 2. Endoscopic images of the diverticular peroral endoscopic myotomy technique. (A) Endoscopic view of an epiphrenic diverticula in the distal esophagus, with a clear cap attached to the endoscope tip. $(\mathrm{B}, \mathrm{C}) \mathrm{A}$ mucosal bleb is created approximately $2 \mathrm{~cm}$ proximal to the diverticulum and mucosal incision is performed. (D, E) Tunneling is performed along both sides of the septum, 2-3 cm beyond the gastroesophageal junction using a triangular tip knife. (F) Septum division is performed using the rotatable scissors-type knife. (G-I) Complete esophageal myotomy is extended 2-3 cm beyond the gastroesophageal junction. (J) Clip closure of the mucosotomy.

occurred in less than $7 \%$ of the cases with no associated mortalities. No recurrences were reported; however, the authors admitted that only a small number of patients were followed up for 24 months. ${ }^{20}$

The treatment of ZD using the POEM technique (Z-POEM) can be technically challenging when the initial incision and tunneling are started $2 \mathrm{~cm}$ proximal to the septum. This is mainly due to the limited working space that results in challenging closure at the end of the procedure. Brewer Gutierrez et al. ${ }^{14}$ and Repici et al. ${ }^{21}$ reported an alternative to Z-POEM, 
known as peroral endoscopic septotomy, allowing direct access to the muscular septum as the mucosal bleb is created over the septum without the need for long tunneling. Repici et al. included 20 patients with a short-septum ZD to evaluate the safety and efficacy of this technique. ${ }^{21}$ Myotomy of the septum was successful in all patients, with a mean procedure time of $13.8 \mathrm{~min}$ and no adverse events. Dysphagia improved significantly in $95 \%$ of the patients. There were no recurrences during the mean follow-up duration of 12 months. ${ }^{21}$ We currently perform all Z-POEM procedures using the latter technique, where the incision is started over the septum.

Another multicenter retrospective case series by Yang et al. studied the outcomes of D-POEM in 11 patients with Zenker's and non-Zenker's diverticula with a median follow-up of up to 145 days. $^{22}$ Both technical and clinical success rates of D-POEM were high, at $91 \%$ and $100 \%$, respectively, with mean dysphagia scores decreasing from 2.7 to $0.1(p<0.001)$. No adverse events were reported. ${ }^{22}$ Similarly, Maydeo et al. reported promising results of the POEM technique in both $\mathrm{ZD}$ and $\mathrm{ED}$ in a case series of 25 patients with a 12-month follow-up. ${ }^{23}$ Complete submucosal tunneling septotomy was achieved in a mean time of $36 \mathrm{~min}$ (range, 25-45 min), with 100\% technical success, clinical success in 19/22 (86\%) patients, and a median hospital stay of 5 days. At the 1-year follow-up, the mean Eckardt score decreased significantly, with no major adverse events reported during the procedure. ${ }^{23}$

Two case series, reported by Li et al. and Basile et al., documented the safety and efficacy of treating non-Zenker's diverticula with D-POEM. ${ }^{24,25}$ In both studies, no serious adverse events were reported, and follow-up indicated a significantly decreased modified Eckardt score $(p<0.001)$ and a clinical improvement rate of $85 \%$ with complete or partial regression of dysphagia, respectively. ${ }^{24,25}$

In patients with ED and EMDs, it is unclear whether POEM alone (with division of the LES but without diverticular septotomy) is sufficient. In a study published by Kinoshita et al., 14 patients with ED had significantly improved median Eckardt scores from 5 before POEM to 0 after POEM without septotomy $(p<0.0001){ }^{26}$ The authors concluded that this should be the chosen first-line treatment for patients with ED and EMD, and septotomy (D-POEM) can be an additional option if POEM alone is unsuccessful. ${ }^{26}$

\section{OUTCOMES OF ZENKER'S \\ DIVERTICULUM USING THE PERORAL ENDOSCOPIC MYOTOMY TECHNIQUE COMPARED WITH THOSE OF DIFFERENT TREATMENT TECHNIQUES}

In a recent international multicenter study conducted by Ghamdi et al., published as an abstract, the comparative efficacy of three different techniques for the treatment of $\mathrm{ZD}$ (Z-POEM, flexible and rigid endoscopic diverticulotomy) was evaluated in 158 patients. ${ }^{27}$ The clinical success rate was significantly higher in the Z-POEM group than in the flexible endoscopic diverticulotomy group ( $86.8 \%$ vs. $81.4 \%, p=0.03$ ) and was similar to that in the rigid endoscopic diverticulotomy group $(86.8 \%$ vs. $88.2 \%, p=0.30)$. Severe/fatal adverse events only occurred in the rigid endoscopic diverticulotomy group. The response was durable in most of the patients during follow-up (90.9\% Z-POEM, 85\% flexible and 100\% rigid endoscopic diverticulotomy). ${ }^{27}$

In 2019, Aslan et al. published an abstract reporting the outcomes of a prospective study comparing the standard flexible endoscopic septomyotomy with the Z-POEM technique. ${ }^{28}$ A total of 29 patients were included in the study and divided into two groups. The Z-POEM group had a longer hospital stay with a higher clinical success rate (100\% vs. $80 \%)$ than the standard flexible endoscopic septotomy group. ${ }^{28}$ Similar findings were reported in the abstract by Desai et al., who conducted a retrospective study comparing these two endoscopic techniques. ${ }^{29}$ The follow-up duration in this case series was 18 months, with a significantly higher recurrence rate in the standard endoscopic diverticulotomy group (37.5\% vs. $0 \%)$ and fewer adverse events in the Z-POEM group (14\% vs. $62.5 \%){ }^{29}$ Further prospective and randomized controlled studies are needed to substantiate these findings.

Cerchione et al. performed an indirect comparison of Z-POEM and the surgical stapled diverticulostomy technique and reported a lower recurrence rate in the Z-POEM group than in the surgical group ( $1 \%$ vs. $10 \%){ }^{30}$ There were no significant differences in terms of clinical success and complications. Both procedures were safe, and adverse events occurred in $2 \%-6 \%$ of the cases. ${ }^{30}$

\section{CONCLUSIONS}

D-POEM is an exciting addition to the treatment armamentarium for esophageal diverticula. Preliminary data suggest the efficacy and safety of the procedure when performed by experienced endoscopists. Z-POEM is best performed over the septum, which simplifies the procedure and mucosal closure. Large multicenter trials are needed to confirm the efficacy and safety of D-POEM and compare its outcomes with those of other available techniques.

Conflicts of Interest

Mouen A. Khashab is a consultant at Boston Scientific, GI Supply, Olym- 
pus America, and Medtronic. The other authors have no financial conflicts of interest.

ORCID

Bogdan P. Miutescu: https://orcid.org/0000-0002-5336-5789

Sarah Khan: https://orcid.org/0000-0002-3471-1738

Shruti Mony: https://orcid.org/0000-0002-6726-337X

\section{Supplementary Materials}

Video 1. Diverticular peroral endoscopic myotomy technique using a scissors-type knife for Zenker's diverticulum (https://doi.org/10.5946/ ce.2020.262.v001).

Video 2. Diverticular peroral endoscopic myotomy technique for epiphrenic diverticula (https://doi.org/10.5946/ce.2020.262.v002).

\section{REFERENCES}

1. Herbella FA, Patti MG. Modern pathophysiology and treatment of esophageal diverticula. Langenbecks Arch Surg 2012;397:29-35.

2. Aiolfi A, Scolari F, Saino G, Bonavina L. Current status of minimally invasive endoscopic management for Zenker diverticulum. World J Gastrointest Endosc 2015;7:87-93.

3. Inoue $\mathrm{H}$, Minami $\mathrm{H}$, Kobayashi $\mathrm{Y}$, et al. Peroral endoscopic myotomy (POEM) for esophageal achalasia. Endoscopy 2010;42:265-271.

4. Nabi Z, Nageshwar Reddy D, Ramchandani M. Recent advances in third-space endoscopy. Gastroenterol Hepatol (N Y) 2018;14:224-232.

5. Li QL, Chen WF, Zhang XC, et al. Submucosal tunneling endoscopic septum division: a novel technique for treating Zenker's diverticulum. Gastroenterology 2016;151:1071-1074.

6. Smith CD. Esophageal strictures and diverticula. Surg Clin North Am 2015;95:669-681.

7. Sonbare DJ. Pulsion diverticulum of the oesophagus: more than just an out pouch. Indian J Surg 2015;77:44-48.

8. Bizzotto A, Iacopini F, Landi R, Costamagna G. Zenker's diverticulum: exploring treatment options. Acta Otorhinolaryngol Ital 2013;33:219229.

9. Yuan Y, Zhao YF, Hu Y, Chen LQ. Surgical treatment of Zenker's diverticulum. Dig Surg 2013;30:207-218

10. Ferreira LE, Simmons DT, Baron TH. Zenker's diverticula: pathophysiology, clinical presentation, and flexible endoscopic management. Dis Esophagus 2008;21:1-8.

11. Gonzalez-Calatayud M, Targarona EM, Balague C, Rodriguez-Luppi C, Martin AB, Trias M. Minimally invasive therapy for epiphrenic diverticula: systematic review of literature and report of six cases. J Minim Access Surg 2014;10:169-174.

12. Brandeis AE, Singhal S, Lee TH, Mittal SK. Surgical management of epiphrenic diverticulum: a single-center experience and brief review of literature. Am J Surg 2018;216:280-285.

13. Ballehaninna UK, Shaw JP, Brichkov I. Traction esophageal diverticulum: a rare cause of gastro-intestinal bleeding. Springerplus 2012;1:50.

14. Brewer Gutierrez OI, Ichkhanian Y, Spadaccini M, Vosoughi K, Repici A, Khashab MA. Zenker's diverticulum per-oral endoscopic myotomy techniques: changing paradigms. Gastroenterology 2019;156:2134-2135.

15. Katzka DA, Baron TH. Transoral flexible endoscopic therapy of Zenker's diverticulum: is it time for gastroenterologists to stick their necks out? Gastrointest Endosc 2013;77:708-710.

16. Wilmsen J, Baumbach R, Stüker D, et al. New flexible endoscopic controlled stapler technique for the treatment of Zenker's diverticulum: a case series. World J Gastroenterol 2017;23:3084-3091.

17. Brieau B, Leblanc S, Bordacahar B, et al. Submucosal tunneling endoscopic septum division for Zenker's diverticulum: a reproducible procedure for endoscopists who perform peroral endoscopic myotomy. Endoscopy 2017;49:613-614.

18. Hernández Mondragón OV, Solórzano Pineda MO, Blancas Valencia JM. Zenker's diverticulum: submucosal tunneling endoscopic septum division (Z-POEM). Dig Endosc 2018;30:124.

19. Sato H, Takeuchi M, Hashimoto S, et al. Esophageal diverticulum: new perspectives in the era of minimally invasive endoscopic treatment. World J Gastroenterol 2019;25:1457-1464.

20. Yang J, Novak S, Ujiki M, et al. An international study on the use of peroral endoscopic myotomy in the management of Zenker's diverticulum. Gastrointest Endosc 2020;91:163-168.

21. Repici A, Spadaccini M, Belletrutti PJ, et al. Peroral endoscopic septotomy for short-septum Zenker's diverticulum. Endoscopy 2020;52:563568.

22. Yang J, Zeng X, Yuan X, et al. An international study on the use of peroral endoscopic myotomy (POEM) in the management of esophageal diverticula: the first multicenter D-POEM experience. Endoscopy 2019;51:346-349.

23. Maydeo A, Patil GK, Dalal A. Operative technical tricks and 12-month outcomes of diverticular peroral endoscopic myotomy (D-POEM) in patients with symptomatic esophageal diverticula. Endoscopy 2019;51:1136-1140.

24. Li X, Zhang W, Yang J, et al. Safety and efficacy of submucosal tunneling endoscopic septum division for epiphrenic diverticula. Endoscopy 2019;51:1141-1145.

25. Basile P, Gonzalez JM, Le Mouel JP, Irarrazaval R, Caillo L, Barthet M. Per-oral endoscopic myotomy with septotomy for the treatment of distal esophageal diverticula (D-POEM). Surg Endosc 2020;34:2321-2325.

26. Kinoshita M, Tanaka S, Kawara F, et al. Peroral endoscopic myotomy alone is effective for esophageal motility disorders and esophageal epiphrenic diverticulum: a retrospective single-center study. Surg Endosc 2020;34:5447-5454.

27. Ghamdi SSA, Farha J, Meybodi MA, et al. International multicenter study comparing Z-POEM and flexible/rigid endoscopic Zenker's diverticulotomy. Gastrointest Endosc 2020;91(6 Suppl):AB3-AB4.

28. Aslan F, Yilmaz O, Sengun B, Unlukaplan A, Karahan SN, Kocak E. A new technique in treatment of Zenker diverticulum: submucosal tunneling endoscopic septum division (Z-POEM) versus classic endoscopic septomyotomy techniques. Gastrointest Endosc 2019;89(6 Suppl):AB629.

29. Desai PN, Kabrawala MV. Submucosal tunnelling endoscopic septum division for Zenker's diverticulum (Z POEM): a new emerging technique compared to conventional flexible endoscopic septotomy. Gastrointest Endosc 2019;89(6 Suppl):AB450.

30. Cerchione R, Parise P, Olivari G, et al. Endoscopic management of Zenker's diverticulum: stapling vs . Z-POEM. Shanghai Chest 2020;4:43. 